$\mathrm{DOE} / \mathrm{BC} / 14202--5$

Distribution

DE92 000276

\title{
MICROBIAL ENHANCEMENT OF OII PRODUCTION FROM CARBONATE RESERVOIRS
}

\section{Quarterly Report for the Period January-March 1991}

BY

Ralph S. Tanner

Roy $\mathrm{M}$. Knapp

Michael J. McInerney

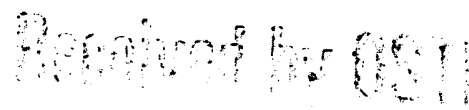

Emmanuel

O. Udegbunam

OCT 071991

Wcrk Performed Under Contract No. AC22-90BC14202

E.B. Nuckols, Project Manager

Metarie Site office

900 Commerce Road, East

New Orleans, LA 70123

University of Oklahoma
Norman, OK 73019

DISCLAIMER

\begin{abstract}
This report was prepared as an account of work sponsrried by an agency of the United States Government. Neither the United States Government nor any agency thereof, nor any of their employees, makes any warranty, express or implied, or assumes any legal liability or responsibility for the accuracy, completeness, or usefulness of any information, apparatus, prodict, or process disclosed, or represents that its use woulc not infringe privately owned rights. Refer-

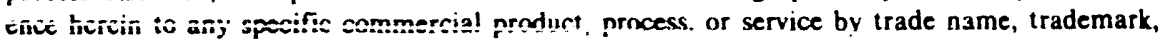
manufacturer, or otherwise does not necessarily constitute or imply its endorsement, recommendation, or favoring by the United States Government or any agency thereof. The views and opinions of authors expressed herein do not necessarily state or reflect those of the United States Government or any agency thereof.
\end{abstract}


MICROBIAL ENHANCEMENT OF OIL RECOVERY FROM CARBONATE RESERVOIRS

Contract \# DE-AC22-90BC14202

University of Oklahoma

Contract Date: $1 / 90$

Anticipated Completion: 5/91

Funding: $\$ 154,482$

Ralph S. Tanner

Roy M. Knapp

Michael J. Mclnerney

Emmanuel O. Udegbunam

Jon P. Adkins

Project Manager: E. B. Nuckols

Metairie Site Office

Reporting Period: January 1 - March 31, 1991

\section{OBJECTIVES}

The goal of this work is to evaluate the potential for MEOR in carbonate reservoirs. Specific objectives include: review of the literature pertinent to MEOR in carbonate reservoirs, a study of the microbial ecology of carbonate reservoirs, isolation of microorganisms from these environments, examination of the effect of microorganisms and their end-products of metabolism on carbonate pore structure, the recovery of residual oil from carbonates in model core systems, and development of models to examine and predict MEOR processes in carbonate reservoirs.

\section{SUMMARY OF TECHNICAL PROGRESS}

\section{Effect of Bacterial Treatment on Carbonate Pore Structure}

An assessment of the effects of microbial activity on the pore structure of carbonate cores is being carried out. Core plugs from rock samples of the Bethany Falls formation, an oolitic grainstone to packstone with oomoldic porosity, have been used by Jenneman, McInerney, and Knapp (1985). The bacterial strains being utilized include: GSP-1, Clostridium acetobutylicum . Bacillus licheniformis strain JF-2, a surfactant producer, and SP018, a polymer producer. Incubation of each strain in the core plugs was generally ten days. Analytical methods used to study the rock pore structure included: electrical conductivity, absolute permeability, porosity, centrifuge capillary pressure and pore size distributions.

Results from these experiments showed that reduction or enlargement in pore 
throat sizes is possible in carbonates depending on the metabolic activity of the selected bacterial strain. Reduction in the pore throat size due to microbial plugging resulted in higher post-treatment residual water saturation, Figure 1, and higher pore entry pressures as well as reductions in porosity and absolute permeability values. Incubation of the core plugs with GSP-1, an acid producer, resulted in an enlargement of the pore throat sizes as evidenced by lower post-treatment values for the irreducible water saturation, Figure 2, and pore entry (threshold) pressure. A slight increase in porosity and permeability was also observed.

An abstract for this aspect of the work entitled "Assessing the Effects of Microbial Enhanced Oil Recovery on Pore Structures of Rocks" has been accepted as SPE Paper 22846 and will be presented at the SPE 66th Annual Technical Conference and Exhibition in Dallas, Texas, October 6 - 9, 1991.

\section{Oil Recovery from Carbonates}

Experiments designed to study oil recovery mechanisms likely to mobilize residual oil from carbonates under varying wetting conditions are in progress. Residual oil saturation was obtained by mimicking the saturation history obtainable in reservoirs for different wetting conditions. Table 1 lists the characteristics and treatment conditions for the Viola limestone chip packs utilized for oil recovery experiments. A water-wet system with hexadecane, core PV-1, underwent four nutrient treatments after the initial inoculation treatment with GSP-1. The pressure versus time data given in Figure 3 indicates a build-up of cell mass in the core system with additional nutrient treatments. No oil was recovered from core PV-1, and it was dismantled after the fifth treatment. Modification of the core matrix was indicated by the presence of calcium in the core effluents and significant amounts of carbonate fines found in the dissected core, presumably caused by metabolic acid dissolution of the carbonate matrix

The other packed Viola limestone cores, PV-2, PV-3 and PV-4, were set up as oil-wet systems using a 34 API gravity crude oil. Core PV-2 was inoculated with GSP. 1; core PV-3 was set up as an uninoculated control. Core PV-4 was shut-in with a cell free supernatant of GSP-1, pH 4.70, to examine the effect of end-products of metabolism on the core matrix in the absence of cells. Cores PV-2 and PV-3 have had two treatments, PV -4 has had one end-product treatment. Preliminary results from these early treatments indicate that significant amounts of oil can be recovered from these oil-wet systems.

\section{REFERENCES}

1. Jenneman, G.E., M.J. Mclnerney, and R.M. Knapp. 1985. Microbial Peneiration through Nutrient Saturated Berea Sandstone. Appl. Environ. Microbiol. 50 : 383 - 391. 
Figure 1. Capillary Pressure Curves of Bethany Falls Limestone Core BF-16 Treated with SP018.

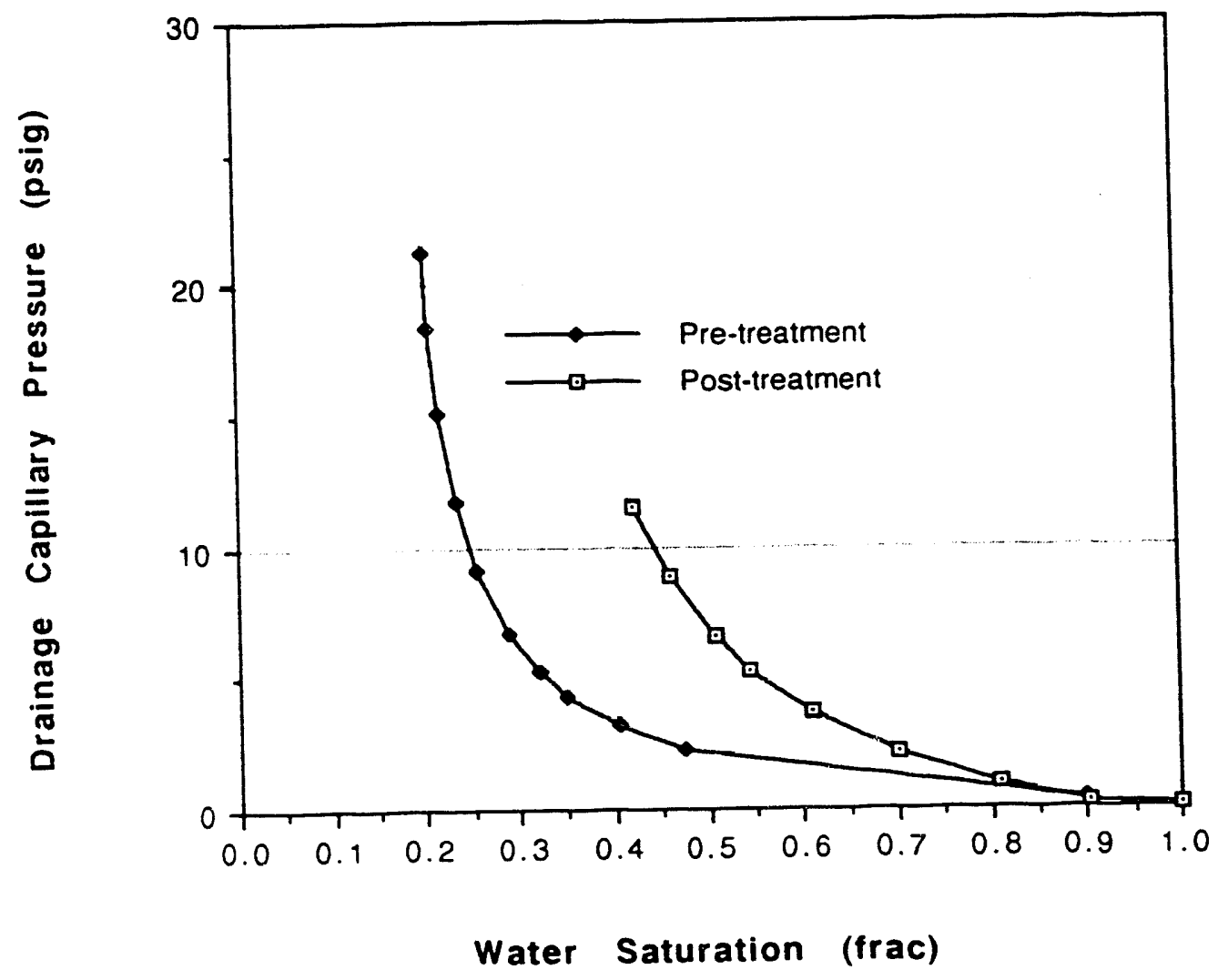


Figure 2. Capillary Pressure Curves Of Bethany Falls Limestone Core BF-3 Treated with GSP-1.

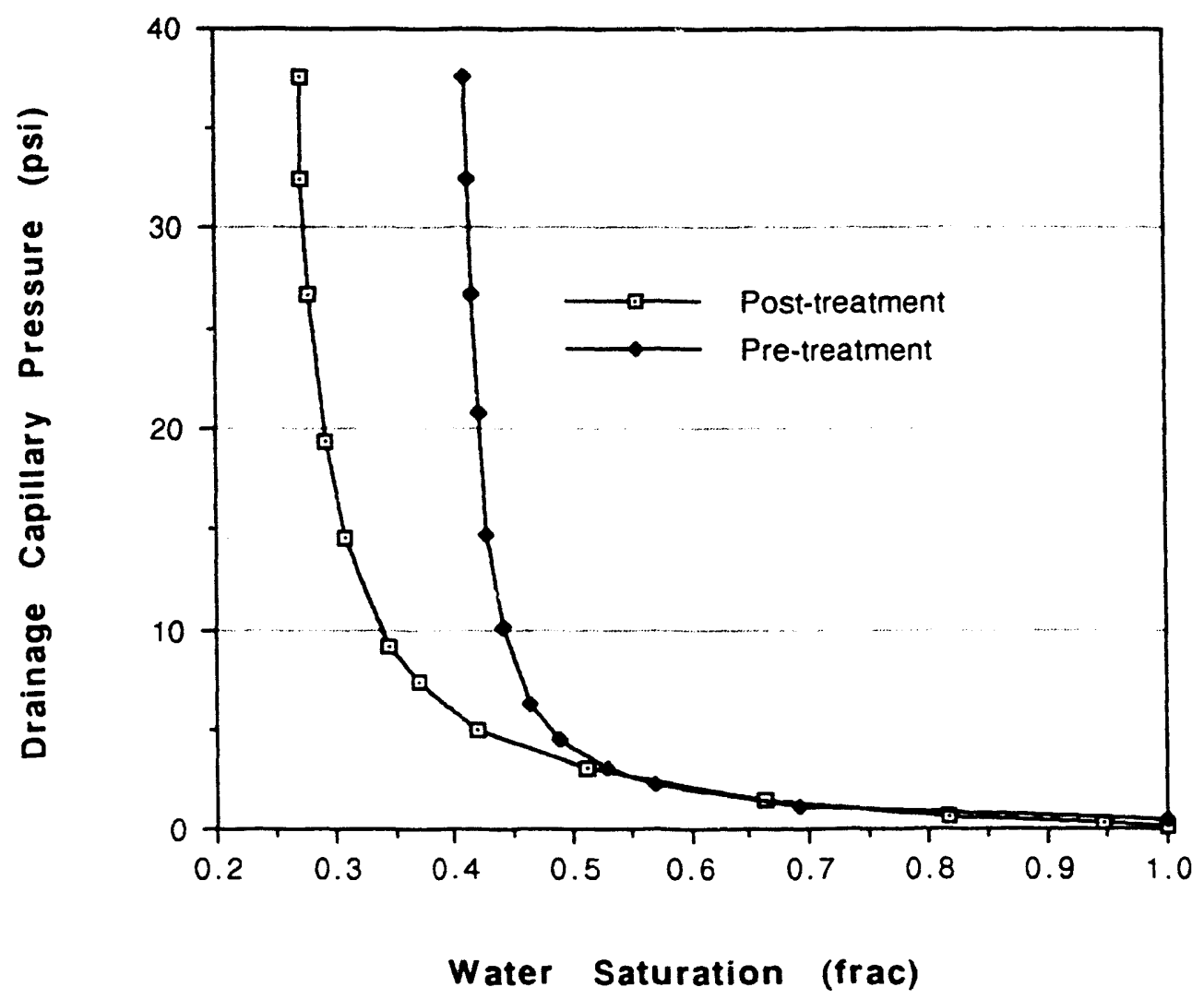


Table 1. Characteristics and Treatment Conditions of Packed Viola Limestone Chip Cores Utilized in Oil Recovery Experiments.

\begin{tabular}{lclll}
\hline & PV-1 & PV-2 & PV-3 & PV-4 \\
Wettability & WW & OW & OW & OW \\
Oil & hexadecane & crude & crude & crude \\
Pore Volume (ml) & 282 & 196 & 170 & 166 \\
Porosity & $35 \%$ & $52 \%$ & $45 \%$ & $44 \%$ \\
Abs. Perm (K) & $21.9 \mathrm{D}$ & $21.2 \mathrm{D}$ & $17.8 \mathrm{D}$ & $38.4 \mathrm{D}$ \\
\hline
\end{tabular}

a $\mathrm{WW}=$ water-wet, $\mathrm{OW}=$ oil-wet. 
Figure 3. Pressure vs. Time Data for PV-1.

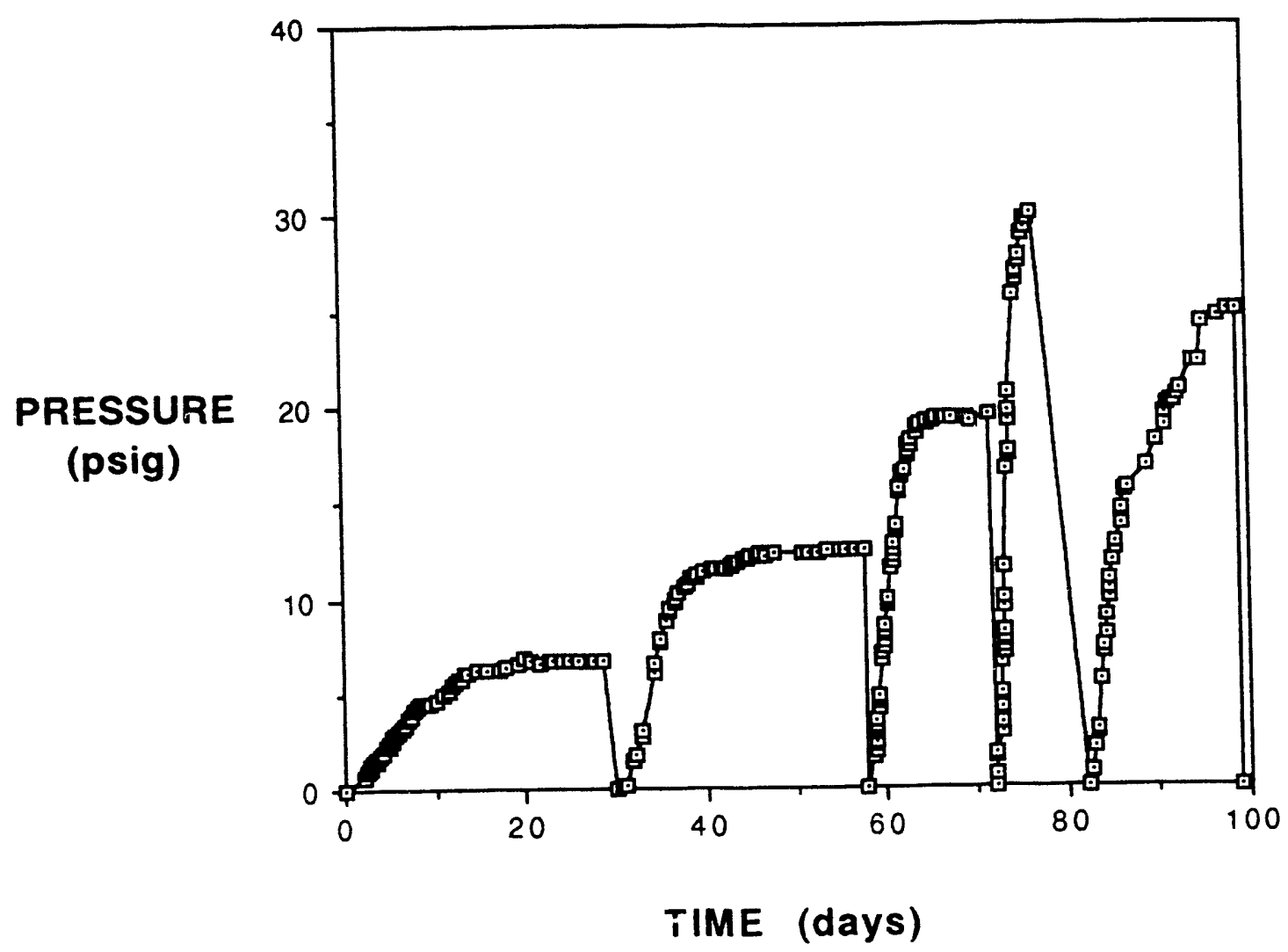



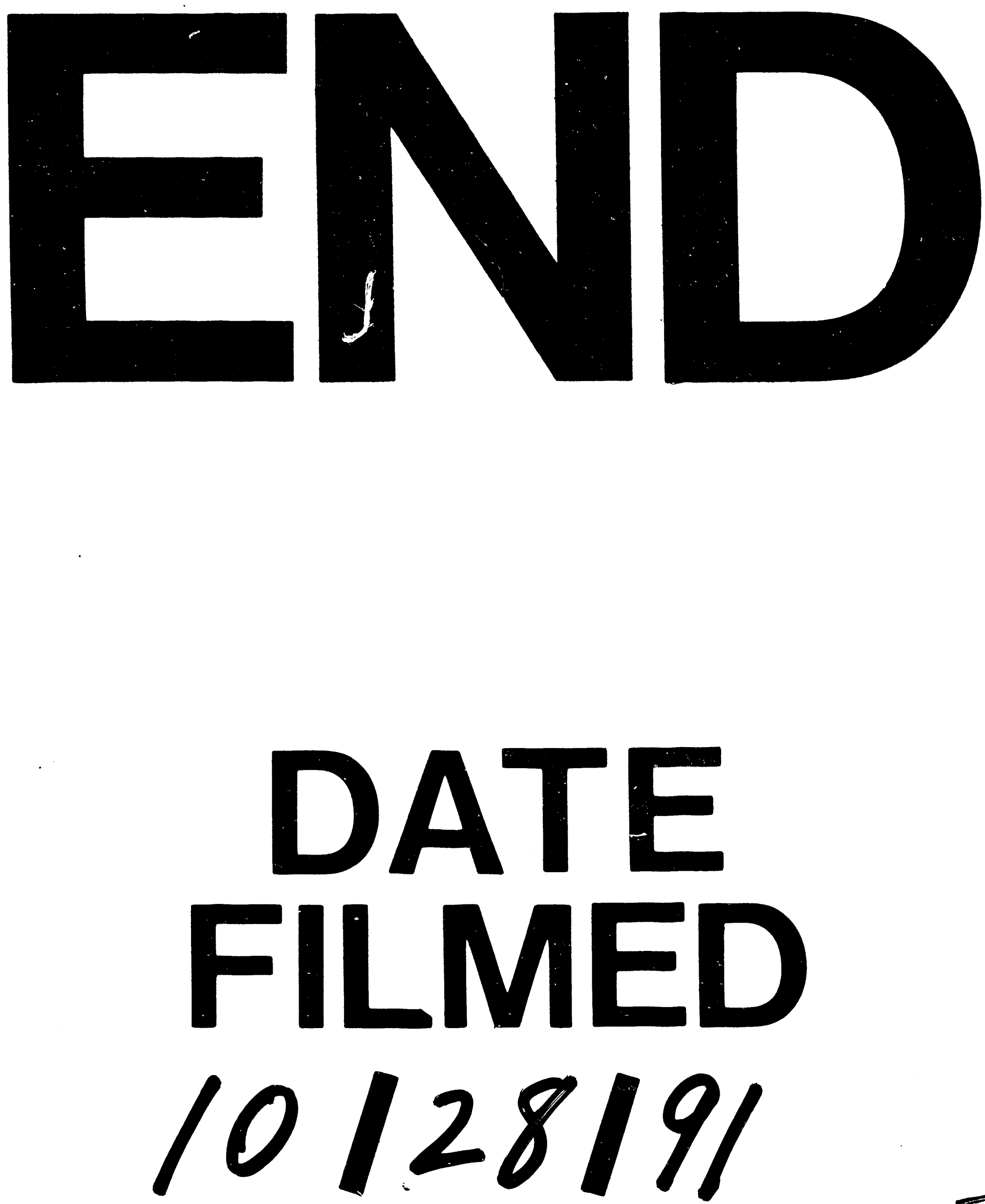
